\title{
Prevalence of non-albicans Candida species versus Candida albicans in critical care patients of a tertiary care hospital
}

\author{
Sharma $\mathbf{P}^{1}$, Kaur $\mathbf{J}^{2}$, Sharma $\mathrm{S}^{3}$ \\ ${ }^{1}$ Dr. Poonam Sharma, Associate Professor, ${ }^{2}$ Dr. Jasvir Kaur, Post Graduate Student, ${ }^{3}$ Dr. Sarbjeet Sharma, Professor and \\ Head, Department Of Microbiology, SGRDIMSAR, Amritsar, Punjab, India.
}

Address for Correspondence: Dr Poonam Sharma. E-mail: poonam136@ rediffmail.com

\begin{abstract}
Introduction: Candida species are the most common cause of opportune- istic fungal infections. Although C.albicans is most common cause of candidiasis, a shift towards non-albicans Candida species is evident in recent years. The transition of Candida spp. from commensal to a potent pathogen is facilitated by a number of virulence factors viz. adherence to host tissues and medical devices, biofilm formation, and secretion of extracellular hydrolytic enzymes. Objective: To study the prevalence of C.albicans \& Non-albicans isolates in critical care settings and determine their virulence factors and antifungal susceptibility profile. Material \& Methods: The present study was carried out in the Department of Microbiology, SGRIMSAR, Amritsar during the period of July 2014 to June 2016. Candida strains isolated from various clinical samples received from different ICUs of the hospital were included in the study. The isolates were identified upto species level by both conventional and automated methods (vitek 2 compact system) as per CLSI guidelines. Relevant history of all the patients was taken. They were also screened for the production of virulence factors such as biofilm formation, haemolytic activity, and production of extracellular hydrolytic enzymes i.e. coagulase. Results: Out of the 115 isolates obtained from various ICUs, most common isolate was $C$. tropicalis 60/115(52.17\%) followed by $C$. albicans 45/115(39.13\%), C.utilis 7/115(6.25\%). Isolates of C. lusitaniae, C. parasillosis \& C. glabrata were 1/115 $(0.86 \%)$ each. Among these 95/115(82.6\%), 75/115(65.2\%), and 83/115(72.17\%) isolates showed biofilm formation, coagulase production and haemolytic properties respectively. Conclusions: Our study showed a shift among Candida species from albicans $(39.13 \%)$ to non-albicans $(60.86 \%)$, thus stressing their presence as major fungal pathogens in critical care settings.
\end{abstract}

Key words: Non-albicans candida, Critical care units, Prevalence, Candida albicans

\section{Introduction}

Candida species are the most common cause of opportunistic fungal infections, resulting in a variety of manifestations ranging from mucocutaneous lesions to life threatening invasive diseases particularly in immunocompromised patients [1]. Although Candida albicans is the most common cause of candidiasis, a shift towards non albicans candida species is evident in recent years [2]. The problem of emergence of Non albicans candida has become more acute because different species of the same exhibit varying degrees of resistance either intrinsic or acquired or both, to commonly used antifungal drugs. C.tropicalis is one of the most common Non-Candida albicans species isolated from various clinical types of candidiasis [3].

Manuscript received: $26^{\text {th }}$ September 2016

Reviewed: $7^{\text {th }}$ October 2016

Author Corrected: $16^{\text {th }}$ October 2016

Accepted for Publication: $30^{\text {th }}$ October 2016
In India, it is the most common cause of health care associated candidemia [4]. The increased isolation of $C$. tropicalis from various clinical types of candidiasis is of concern because of its ability to develop resistance to fluconazole [5].

The transition of Candida spp. from commensal to potent pathogens is facilitated by a number of virulence factors such as adherence to host tissues and medical devices, biofilm formation, and secretion of extracellular hydrolytic enzymes [6].

The present study was therefore conducted in a tertiary care teaching hospital of North India with the aim of knowing the prevalence of $C$. albicans \& Non-albicans isolates in critical care settings and determine their virulence factors and antifungal susceptibility profile. 


\section{Material and Methods}

Ours was a prospective study, carried out in the Mycology section of Microbiology department of SGRDIMSAR, Amritsar during a period of 2 years from July 2014 to June 2016. Candida species isolated from various clinical specimens from different ICUs of the hospital were included in the study. Patient's information such as duration of hospitalisation, ward, underlying medical conditions, associated risk factors such as presence of urinary catheter, respiratory ventilation, central line insertion, duration of antibiotic therapy, antifungal prophylaxis, exposure to invasive medical procedures, and use of corticosteroids was obtained from clinical records and analysed. The isolates collected were consecutive and were derived from various clinical samples including blood, urine, foley's catheter tip, vaginal discharge etc. Blood culture samples collected in blood culture bottles were incubated in BacT alert 3D (Biomerieux) automated blood culture system and upon getting a positive alarm were subcultured onto Sabouraud's Dextrose Agar \& blood agar plates. Samples were processed for microscopy and culture using standard mycological procedures. Candida isolates were characterized by colony morphology, gram staining, germ tube formation, chlamydospore formation on corn meal agar, growth on CHRO Magar candida medium. The isolates were identified upto species level \& their antifungal susceptibility was done by automated method (vitek 2 compact). Virulence of all the isolates was assessed by Biofilm production assay, detection of haemolytic activity and the production of extracellular hydrolytic enzymes eg.coagulase [6,7].

\section{Results}

Out of a total of 300 Candida species isolated from clinical samples, 115 were obtained from patients admitted in various ICUs (MICU, MEDICU, SICU, NICU, PICU, BICU etc.). Among the latter the most common isolate was C.tropicalis (52.17\%), followed by C.albicans $(39.13 \%) \&$ C.utilis $7 / 115$ as shown in Table 1 . The formation of biofilm, coagulase \& haemolysin production by various species of Candida is shown in Table 2. Most of the isolates which were virulent showed biofilm formation and coagulase production. Isolates of C.lusitaniae, C.parapsillosis \& C.glabrata were 1 $(0.86 \%)$ each. Antifungal susceptibility testing in our study showed nearly similar resistance to fluconazole by C.albicans $(22.22 \%)$ \& Candida non albicans $(28.5 \%)$ as shown in Table 2.

Table-1: Candida spp isolated from various clinical specimens.

\begin{tabular}{|l|l|l|l|l|l|}
\hline Candida species & No. of isolates & Urine & Blood & Foley's Catheter tip & $\begin{array}{l}\text { Suction } \\
\text { Endotracheal tube }\end{array}$ \\
\hline C.tropicalis & $60(52.17 \%)$ & $26(43.33 \%)$ & $1(1.67 \%)$ & $25(41.67 \%)$ & $8(13.34 \%)$ \\
\hline C.albicans & $45(39.13 \%)$ & $19(42.23)$ & 0 & $21(46.67 \%)$ & $5(11.12 \%)$ \\
\hline C.glabrata & $1(0.86 \%)$ & 0 & 0 & $1(100 \%)$ & 0 \\
\hline C.utilis & $7(6.08 \%)$ & 0 & $7(100 \%)$ & $0(0 \%)$ & 0 \\
\hline C.lusitaniae & $1(0.86 \%)$ & 0 & $1(100 \%)$ & 0 & 0 \\
\hline C.parasillosis & $1(0.86 \%)$ & $1(100 \%)$ & 0 & 0 & 0 \\
\hline Total & $\mathbf{1 1 5}$ & $\mathbf{4 6}(\mathbf{4 0 \%})$ & $\mathbf{9 ( 7 . 8 2 \% )}$ & $\mathbf{4 7}(\mathbf{4 0 . 8 6 \% )}$ & $\mathbf{1 3 ( 1 1 . 3 0 \% )}$ \\
\hline
\end{tabular}

Table-2: Production of various virulence factors by Candida spp

\begin{tabular}{|l|l|l|l|l|}
\hline Candida species & $\begin{array}{l}\text { No. of isolates } \\
\text { \% }\end{array}$ & $\begin{array}{l}\text { Biofilm formation } \\
\text { assay }\end{array}$ & Coagulase production & Haemolysin production \\
\hline C.tropicalis & 60 & $56(93.34 \%)$ & $40(66.67 \%)$ & $43(71.67 \%)$ \\
\hline C.albicans & 45 & $40(88.89 \%)$ & $32(71.12 \%)$ & $39(86.67 \%)$ \\
\hline C.glabrata & 1 & $1(100 \%)$ & $1(100 \%)$ & $1(100 \%)$ \\
\hline C.utilis & 7 & $7(100 \%)$ & $0(0 \%)$ & $0(0 \%)$ \\
\hline C.lusitaniae & 1 & $1(100 \%)$ & $1(100 \%)$ & 0 \\
\hline C.parapsilosis & 1 & $1(100 \%)$ & $1(100 \%)$ & 0 \\
\hline Total & $\mathbf{1 1 5}$ & $\mathbf{1 0 6}(\mathbf{9 2 . 1 7 \%})$ & $\mathbf{7 5}(\mathbf{6 5 . 2 \%})$ & $\mathbf{8 3 ( 7 2 . 1 7 \% )}$ \\
\hline
\end{tabular}


However resistance to Amphotericin B by Candida albicans (11.33\%) was almost one third compared to non albicans (33.33\%). Further, all isolates of C.albicans were susceptible to Caspofungin, reduced susceptibility was observed in only one isolate of C.lusitaniae, a non albicans strain. Resistance to Flucytosine was however observed in 5/45 (11.33\%) Candida albicans \& 10/70 (14.28\%) Candida non albicans. All the isolates in our study were found to be totally susceptible to Voriconazole and Micafungin.

Table-3: Antifungal susceptibility pattern.

\begin{tabular}{|c|c|c|c|}
\hline Antifungal Drugs & $\begin{array}{l}\text { C.albicans } \\
45 / 115 \\
(39.13 \%)\end{array}$ & $\begin{array}{l}\text { Candida non-albicans } \\
70 / 115 \\
(60.86 \%) \\
\end{array}$ & $\begin{array}{l}\text { Total } \\
115\end{array}$ \\
\hline $\begin{array}{l}\text { Fluconazole } \\
\text { Resistance } \\
\text { Intermediate } \\
\text { Sensitive } \\
\end{array}$ & $\begin{array}{l}10(22.22 \%) \\
5(11.11 \%) \\
30(66.67 \%)\end{array}$ & $\begin{array}{l}20(28.5 \%) \\
3(4.28 \%) \\
47(67.14 \%)\end{array}$ & $\begin{array}{l}30(26.08 \%) \\
8(6.95 \%) \\
77(69.95 \%)\end{array}$ \\
\hline $\begin{array}{l}\text { Voriconazole } \\
\text { Resistance } \\
\text { Intermediate } \\
\text { Sensitive } \\
\end{array}$ & $\begin{array}{l}0 \\
0 \\
45(100 \%)\end{array}$ & $\begin{array}{l}0 \\
0 \\
70(100 \%)\end{array}$ & $\begin{array}{l}0 \\
0 \\
113(98.2 \%)\end{array}$ \\
\hline $\begin{array}{l}\text { Amphotericin B } \\
\text { Resistance } \\
\text { Intermediate } \\
\text { Sensitive }\end{array}$ & $\begin{array}{l}5(11.11 \%) \\
10(22.22 \%) \\
30(66.67 \%)\end{array}$ & $\begin{array}{l}15(33.33 \%) \\
10(14.28 \%) \\
45(64.28 \%)\end{array}$ & $\begin{array}{l}20(17.39 \%) \\
20(17.39 \%) \\
75(65.21 \%)\end{array}$ \\
\hline $\begin{array}{l}\text { Flucytosine } \\
\text { Resistance } \\
\text { Intermediate } \\
\text { Sensitive }\end{array}$ & $\begin{array}{l}5(11.11 \%) \\
0 \\
40(88.89 \%)\end{array}$ & $\begin{array}{l}10(14.28 \%) \\
0 \\
60(85.17 \%)\end{array}$ & $\begin{array}{l}15(13.04 \%) \\
0 \\
100(86.95 \%)\end{array}$ \\
\hline $\begin{array}{l}\text { Micafungin } \\
\text { Resistance } \\
\text { Intermediate } \\
\text { Sensitive }\end{array}$ & $\begin{array}{l}0 \\
0 \\
45(100 \%)\end{array}$ & $\begin{array}{l}0 \\
0 \\
70(100 \%)\end{array}$ & $\begin{array}{l}0 \\
0 \\
115(100 \%)\end{array}$ \\
\hline $\begin{array}{l}\text { Caspofungin } \\
\text { Resistance } \\
\text { Intermediate } \\
\text { Sensitive }\end{array}$ & $\begin{array}{l}0 \\
0 \\
45(100 \%)\end{array}$ & $\begin{array}{l}1(1.42 \%) \\
0 \\
69(98.57 \%)\end{array}$ & $\begin{array}{l}1(0.86 \%) \\
0 \\
114(99.13 \%)\end{array}$ \\
\hline
\end{tabular}

\section{Discussion}

In our study, we observed that isolates of non-albicans Candida had predominance over C.albicans similar to various other studies from different parts of the world [8,9]. Also C.tropicalis followed by C.albicans were the most common species isolated which is in concordance with other studies [3,10]. Non candida albicans were more prevalent in urine, foley's catheter tip \& respiratory samples.We also observed 7 cases of C.utilis candedemia in neonatal ICU patients within a period of 2 months in 2016. All these pateints were premature, critically ill, had low birth weight, were on ventilator, on multi drug antibiotic therapy and on total parenteral nutrition. One of them was operated for tracheo-esophageal fistula. 2 of them had oral candidiasis. Repeated isolation of C.utilis from the blood samples has been shown in other studies as well
[11]. Biofilm production assay was positive in all C.utilis strains which indicates the potential pathogenicity of this strain. All of them were being treated with Fluconazole which was started empirically even before sending the blood samples for culture. Inspite of the treatment with Fluconazole, candidemia did not resolve. Similar results were observed in a study by Bougnoux et alin 1993 \& AmarelaLukic-Grlic et al in 2011[11,12]. One similar case of candidemia with C.utilis has been reported in a new born baby by Jayasree Shivadasan et al [13]. Factors like biofilm production, coagulase production \& production of extracellular hydrolytic enzymes such as coagulase indicates virulence of Candida species [14]. Biofilm production was seen in $89 \%$ of C.albicans \& $62.2 \%$ isolates of non candida albicans in the current study. 
Research Article

Other virulence factors viz. coagulase production and haemolytic activity were also observed respectively in $71.12 \%$ and $86.67 \%$ of Candida albicans. However non candida albicans also showed $57.33 \%$ \& $53.01 \%$ coagulase production and haemolytic properties respectively which again indicates the increasing virulence of non candida albicans species [14,15]. Among all candida isolates C.tropicalis showed more (93.34\%) ability ofbiofilm formation which has been observed in other studies also [16]. The notable finding was one isolate of C.glabrata which showed presence of all the virulence factors.

Antifungal susceptibility pattern observed in our study showed that among all the resistant strains of Candida sp., maximum resistance was observed with Fluconazole and Amphotericin B. In comparison to C.albicans isolates, non albicans strains showed more resistance to both Fluconazole and Amphotericin B. Among the latter, C.tropicalis, the most common strain in our study, was found to be almost sensitive to all the antifungals.

Only one isolate of C.lusitania, which was obtained from the blood of a 5year old child, was found to be resistant to Caspofungin however it was susceptible to Fluconazole.

\section{Conclusion}

So far non albicans-Candida has been considered non pathogenic, however trends are changing with time. Our study showed a shift among Candida species from albicans $(39.13 \%)$ to non-albicans $(60.86 \%)$, thus stressing their emergence as major fungal pathogens.

Presence of non albicans-Candida in any specimen therefore cannot be ignored now, especially in the critically ill patients of any age, keeping in mind their potential to become resistant to many antifungal drugs routinely used.

Conflict of Interests- The authors declare that there is no conflict of interests regarding the publication of this paper.

Funding: Nil, Conflict of interest: None initiated, Permission from IRB: Yes

\section{References}

1. Chander J. Opportunistic mycoses. In: ChanderJ, editor. Text book Of Medical Mycology. Mehta publishers. $3^{\text {rd }}$ ed. 2011. 266-90.
2. Deorukhkar SC, Saini S and Mathew S. Non-albicans Candida Infection: An Emerging Threat. Interdisciplinary Perspectives on Infectious Diseases. 2014;1-7

3. Paul N, Mathai E, Abraham OC, Mathai D. Emerging microbiological trends in Candiduria. Clin Infect Dis. 2004 Dec 1;39(11):1743-4.

4. Giri S, Kindo AJ. A review of Candida species causing blood stream infection. Indian $\mathrm{J}$ Med Microbiol. 2012 Jul-Sep;30(3):270-8. doi: 10.4103/ 0255-0857.99484.

5. Pahwa N, Kumar R, Nirkhiwale $S^{1}$, Bandi A. Species distribution and drug susceptibility of candida in clinical isolates from a tertiary care centre at Indore. Indian J Med Microbiol. 2014 Jan-Mar;32(1):44-8. doi: 10.4103/0255-0857.124300.

6. Deorukhkar SC, Saini S, Mathew S. Virulence Factors Contributing to Pathogenicity of Candida tropicalis and Its Antifungal Susceptibility Profile. Int J Microbiol. 2014;14:1-6.

7. Kumari V, Banerjee T, Kumar P et al. Emergence of non-albicans Candida among candidalvulvovaginitis cases and study of their potential virulence factors, from a tertiary care center, North India..IJPM 2013;56:144-7.

8. de Oliveira RD, Maffei CM, Martinez R. [Nosocomial urinary tract infections by Candida species]. Rev Assoc Med Bras (1992). 2001 Jul-Sep; 47(3):231-5.

9. Oberoi J K, Wattal C, Goel N, Raveendran R, Datta S \& Prasad K.. Non-albicans Candida species in blood stream infections in a tertiary care hospital at New Delhi, India. Indian J Med Res 2012; 136: 997-1003.

10. Jain M, Dogra V, Mishra B, Thakur A, Loomba PS, Bhargava A. Candiduria in catheterized intensive care unit patients: emerging microbiological trends. Indian J Pathol Microbiol. 2011 Jul-Sep;54(3):552-5. doi: 10. 4103/0377-4929.85091.

11. Bougnoux ME, Gueho E, Potocka AC. Resolutive Candida utilis fungemia in a nonneutropenic patient. J Clin Microbiol. 1993 Jun;31(6):1644-5.

12. Lukić-Grlić A, Mlinarić-Missoni E, Skarić I, VazićBabić V, Svetec IK. Candida utilis candidaemia in neonatal patients. J Med Microbiol. 2011 Jun;60(Pt 
6):838-41. doi: 10.1099/jmm.0.023408-0. Epub 2011 Feb 24.

13. Shivadasan J, Raksha, Prashanth S Urs. Candida utilis causing neonatal Candidemia - A case report and literature review. Apollo Medicine. 2016;13 (1): 55-8.

14. Rodrigues AG, Pina-Vaz C, Costa-de-Oliveira S, Tavares C. Expression of plasma coagulase among pathogenic Candida species. J Clin Microbiol. 2003 Dec;41(12):5792-3.
15. Yigit N, Aktas AE, Ayyildiz A. Detection of coagulase activity in pathogenic Candida species. J Int Med Res. 2008 Nov-Dec;36(6):1378-82.

16. Bizerra FC, Nakamura CV, de Poersch C, Estivalet Svidzinski TI, Borsato Quesada RM, Goldenberg S, Krieger MA, Yamada-Ogatta SF. Characteristics of biofilm formation by Candida tropicalis and antifungal resistance. FEMS Yeast Res. 2008 May;8(3):442-50. doi: 10.1111/j.1567-1364.2007.00347.x. Epub 2008 Jan 29.

\section{How to cite this article?}

Sharma P, Kaur J, Sharma S.Prevalence of non-albicans Candida species versus Candida albicans in critical care patients of a tertiary care hospital. Trop J Path Micro 2016;2(3):89-93.doi: 10.17511/jopm.2016.i03.02 